\title{
TATA KELOLA HUBUNGAN MASYARAKAT DI LEMBAGA PENDIDIKAN KUTTAB
}

\author{
Irfan Setia Permana ${ }^{1}$, Ari Prayoga ${ }^{2}$, Della Shelvira ${ }^{3}$ \\ Email:irfanspw@poltektedc.ac.id,ari.prayoga@uinsgd.ac.id, \\ dellashelvira@saibnuhajar.sch.id
Politeknik TEDC Bandung ${ }^{1}$, UIN Sunan Gunung Djati Bandung², Sekolah Alam Ibnu Hajar Bogor ${ }^{3}$

\begin{abstract}
Kuttab is considered foreign to some people so that the public is still familiar with the concept of kuttab education. Historically, the Muslim community did not allow the Kuttab to be separate and there were boundaries with society. It is for this that the Kuttab correlates with its people and joins in their daily lives. The existence of a barrier between kuttab and society can affect people's beliefs and participation. The purpose of this research is to identify and describe the Governance of Public Relations in Kuttab Al Fatih Bandung from planning, implementation, assessment, to supporting and inhibiting aspects of public relations at Kuttab Al Fatih Bandung. The method used in this research is qualitative. Data collection used observation procedures, interviews and documentation research. The data validity test used the participation extension technique, observer intensity, triangulation, peer checking, referral adequacy, negative problem analysis, member checking, detailed explanation and auditing. The results of this research show that the governance of public relations in Kuttab Al Fatih Bandung is running well even though this task is held by the official Kuttab and the Tawaf division. First, planning refers to the vision, mission and profile of Kuttab Al Fatih Bandung which refers to the Al-Quran, hadith and the prophet's sirah. Second, implementation is carried out by implementing planned programs that involve all kuttab stakeholders. Third, evaluation is carried out after programs and activities have been implemented. This evaluation is to take into account the success of the program and deliberate on any cases. Fourth, the supporting aspects of public relations come from internal Kuttab, namely Kuttab's human resources who have a sincere mindset and the intention to worship when carrying out all activities. The factors inhibiting citizen ties come from externals, namely parents and residents who have different descriptions of the concept of Kuttab education.
\end{abstract}

Keyword: Governance; public relations; kuttab.

ABSTRAK: Kuttab dianggap asing untuk sebagian masyarakat sehingga publik masih membiasakan diri dengan konsep pendidikan kuttab. Bagi sejarahnya masyarakat muslim tidak membolehkan Kuttab terpisah serta terdapat pembatas dengan masyarakat. Untuk itulah Kuttab korelasi dengan masyarakatnya serta bergabung dalam kehidupan setiap hari mereka. Adanya pembatas antara kuttab serta masyarakat dapat mempengaruhi terhadap keyakinan serta partisipasi masyarakat. Tujuan dari riset ini merupakan untuk mengenali serta mendeskripsikan Tata kelola Hubungan Masyarakat di Kuttab Al Fatih Bandung dari perencanaan, implementasi, penilaian, hingga aspek pendukung serta penghambat humas di Kuttab Al Fatih Bandung. Metode yang digunakan dalam riset ini merupakan kualitatif. Pengumpulan data memakai prosedur observasi, wawancara serta riset dokumentasi. Adapun uji keabsahan data memakai teknik perpanjangan keikutsertaan, intensitas pengamat, triangulasi, pengecekan teman sejawat, kecukupan rujukan, analisa permasalahan negatif, pengecekan anggota, penjelasan rinci serta auditing. Hasil riset ini menunjukkan jika tata kelola hubungan masyarakat di Kuttab Al Fatih Bandung berjalan dengan baik walaupun tugas ini dipegang oleh official Kuttab serta divisi Tawaf. Pertama, pembuatan perencanaan mengacu pada visi, misi serta profil Kuttab Al Fatih Bandung yang merujuk kepada Al-Quran, hadits serta sirah nabi. Kedua, implementasi dilakukan dengan melaksanakan program-program yang sudah direncanakan yang melibatkan seluruh stakeholder kuttab. Ketiga, evaluasi dilakukan sesudah program maupun aktivitas telah dilaksanakan. Evaluasi ini untuk memperhitungkan keberhasilan program serta me-musyawarahkan apabila terjadi kasus. Keempat, aspek pendukung hubungan masyarakat berasal dari internal Kuttab ialah sumberdaya manusia Kuttab yang mempunyai mindset ikhlas serta niat untuk beribadah ketika melaksanakan seluruh aktivitas. Faktor penghambat ikatan warga berasal dari eksternal ialah orang tua serta warga yang mempunyai uraian yang berbeda- beda tentang konsep pendidikan Kuttab.

Kata kunci: Tata kelola; hubungan masyarakat; kuttab. 


\section{A. PENDAhuluan}

Kuttab Al Fatih Bandung tidak memiliki ruang khusus untuk divisi hubungan masyarakat, hanya ada ruang untuk menerima tamu yang mana ruangan tersebut berada dalam satu ruangan dengan ruang tata usaha. Ruang ini berada di lantai dua disamping ruang kepala Kuttab yang berada diposisi pojok sebelah kiri. Didalam ruang tersebut terdapat empat kursi yang disusun secara melingkar dan terdapat meja ditengahnya. Diatas meja tersebut telah tersedia air mineral untuk menjamu tamu beserta buku tamu. Buku tamu ini diisi sesuai jenis keperluan tamu. Disamping buku tamu terdapat buku FAQ yang berisi beberapa informasi mengenai Kuttab Al Fatih seperti kurikulum Kuttab dan jadwal belajar di Kuttab. Buku ini disediakan untuk orang tua yang ingin mendaftarkan anaknya di Kuttab ataupun tamu lainnya yang membutuhkan (Faisal, 2019a).

Kuttab Al Fatih merupakan lembaga pendidikan non formal untuk anak umur 5- 12 tahun yang berkonsentrasi pada 2 kurikulum utama, ialah Kurikulum Iman serta Kurikulum Alquran. Sehingga masa Pembelajaran Kuttab Al Fatih sepanjang 7 tahun. Berdirinya Kuttab Al Fatih bermula dari diskusi rutin tentang shirah nabawiyah yang dipandu oleh Ustaz Budi Ashari. Dari sini partisipan dialog menciptakan konsep pembelajaran Kuttab. Catatan sejarah tentang Kuttab masih tersimpan dengan apik. Referensi serta aplikasi lapangan tersusun dengan sempurna. Kriteria pengelola serta pengembangan Lembaga terkonsep dengan baik. Apalagi kurikulumnya disebutkan tanpa ada yang tertutupi. Sampai pada kesimpulannya pada tahun 2012 Pembina Kuttab Al Fatih ialah Ustaz Muhaimin Iqbal bersama Ustaz Budi Ashari, Walid Ilham serta tim angkatan awal mendirikan Kuttab Al Fatih awal di Indonesia yang berbasis 2 kurikulum Iman serta Al- Qur' an. Hingga di tahun 2017 kuttab Al Fatih berlokasi di 25 tempat. Kuttab Al Fatih tidak berafiliasi kemana- mana. Tetapi, Kuttab Al Fatih mempunyai dewan syariah selaku penentu warna serta kekhasan lembaga Kuttab Al Fatih. Dewan syariah itu ditetapkan untuk menjaga ruh Kuttab, fatwa serta fiqih khusus Kuttab Al Fatih saja (Faisal, 2019b).

Pendirian Kuttab Al Fatih Bandung bermula dari hadirnya orang-orang yang mau mengkaji dan merenungi tentang kondisi pendidikan Islam saat ini. Hasil dari perenungan dan kajian tersebut menghantarkan orang-orang tersebut mengenal kuttab Al Fatih yang kemudian melakukan kunjungan ke kuttab Al Fatih Pusat/ Depok pada tahun 2014. Akhirnya dari pihak kuttab Al Fatih Pusat/ Depok mengutus tim perintis yang mempersiapkan pendirian kuttab $\mathrm{Al}$ Fatih cabang Bandung dengan tim yang terdiri dari Ghozi Ghozalfan Farabi Basarah sebagai orang yang mengajukan pendirian Kuttab Al Fatih Bandung, Bambang Wahono, dan Dhika
Kameswara sebagai utusan dari Kuttab Al Fatih Pusat/ Depok yang sekarang menjadi kepala Kuttab Al Fatih Bandung. Kuttab Al Fatih Bandung berdiri sejak bulan Februari 2015 di wilayah Dayeuh Pamokolan Kecamatan Cimenyan dengan dihadiri orang tua-orang tua calon santri, guru-guru Kuttab, aparat kepolisian Polsek Cimenyan, perwakilan dari pemerintahan Desa Cimenyan dan dari pihak MUI kelurahan Cimenyan serta tokoh-tokoh warga dan tokoh-tokoh keagamaan Cimenyan (Faisal, 2019a).

Kuttab Al Fatih Bandung dari tahun pertamanya sampai saat ini telah membuka sebelas kelas. Jumlah guru serta karyawan saat ini sebanyak 35 orang. guru-guru kuttab Al Fatih Bandung banyak berasal dari hampir seluruh perguruan tinggi di bandung serta lembaga tahfidz. Hingga pada tahun 2018 Kuttab Al Fatih Bandung telah memiliki 2 unit diantaranya di Gede Bage yang telah berjalan semenjak tahun 2017 serta di Cileunyi akan berjalan di tahun 2018 ini. Posisi kuttab Al Fatih Bandung terletak di dataran tinggi yang sejuk di perbukitan serta harus melewat banyak tanjakan serta jalur terjal. Jumlah santri kuttab Al Fatih Bandung sebanyak 137 santri dengan sebaran tempat tinggal santri berasal dari kabupaten serta kota Bandung (Bidang Kurikulum, 2019).

Tata kelola Humas dalam pendidikan merupakan mediator yang berada di antara pimpinan sekolah dengan publiknya. Tata kelola hubungan masyarakat menitikberatkan bagaiamana organisasi mampu berinteraksi dengan lingkungan eksternalnya dalam menciptakan suasana yang kondusif bagi organisasi sehingga mampu tumbuh dan berkembang secara cepat dalam mencapai tujuan yang telah ditetapkan (Jahari \& Sarbini, 2013).

Bersumber pada hasil riset pendahuluan melalui wawancara dengan Dhika selaku kepala Kuttab Al Fatih Bandung pada Selasa 12 Desember 2019 menarangkan jika Kuttab Al Fatih merupakan lembaga pembelajaran untuk anak umur lima sampai dengan dua belas tahun yang berkonsentrasi pada dua kurikulum utama, ialah kurikulum Iman serta kurikulum Al- Quran. Kuttab Al Fatih setingkat umur Taman Kanak-kanak hingga dengan Sekolah Dasar kelas enam. Kuttab Al Fatih mempunyai dua jenjang ialah Kuttab Awwal serta Kuttab Qonuni. Kuttab Awwal dibagi jadi tiga tingkat ialah Kuttab Awwal satu, Kuttab Awwal dua serta Kuttab Awwal tiga. Kuttab Qonuni merupakan lanjutan dari Kuttab Awwal. Kuttab Qonuni dibagi jadi empat tingkat, ialah Kuttab Qonuni satu, Kuttab Qonuni dua, Kuttab Qonuni tiga serta Kuttab Qonuni empat. Kuttab Al Fatih ialah lembaga pembelajaran nonformal dengan izin operasionalnya merupakan izin penyelenggaraan Pusat Kegiatan Belajar Masyarakat (PKBM). 
Serupa dengan lembaga pendidikan yang lain, Kuttab Al Fatih Bandung juga sangat menjaga citra baik lembaganya. Konsep pembelajaran Kuttab untuk mayoritas orang terdengar asing sebab konsep ini baru timbul lagi setelah lama tidak diterapkan. Sebaliknya orang tua serta warga berasal dari latar belakang pemahaman yang berbeda. Perihal ini dapat menyebabkan tidak sinergisnya antara orang tua serta warga dengan kuttab yang dapat mempengaruhi terhadap kepercayaan serta partisipasi warga terhadap kuttab. Sementara itu menurut sejarahnya masyarakat muslim tidak membolehkan Kuttab terpisah serta terdapat pembatas dengan warga. Bersumber pada fenomena tersebut bagaimana metode lembaga tersebut supaya bisa memegang kepercayaan warga serta sanggup melindungi dan menjalakan hubungan yang baik antara lembaga serta masyarakat. Hingga perlu adanya kajian lebih lanjut terkait lembaga Kuttab Al Fatih Bandung. Tujuan riset ini ialah untuk menguak penerapan pengelolaan hubungan masyarakat pada lembaga pendidikan kuttab. Teori tata kelola humas mencakup fungsi- fungsi pokok manajemen secara umum; perencanaan, implementasi, serta evaluasi/ penilaian.

\section{B. METODE PENELITIAN}

Pada riset ini menggunakan pendekatan kualitatif, yaitu menggambarkan serta mengungkapkan kenyataan mengenai Tata kelola Hubungan Masyarakat Di Kuttab Al Fatih Bandung, setelah itu dipaparkan secara deskriptif dengan perkata ataupun penjelasan. Metode riset kualitatif bagi (Sugiyono, 2016) merupakan metode riset yang berlandaskan pada filsafat postpositivisme, digunakan untuk mempelajari pada keadaan obyek yang alamiah, (sebagai lawannya merupakan eksperimen) dimana peneliti merupakan selaku instrumen kunci, pengambilan ilustrasi sumber informasi dilakukan secara purposive serta snowball, metode pengumpulan dengan trianggulasi (gabungan), analisa informasi bersifat induktif/ kualitatif, serta hasil riset kualitatif lebih menekankan arti dari pada generalisasi (Moleong, 2017). Riset ini hendak berikan gambaran serta mendeskripsikan secara objektif, faktual serta mendalam terkait tata kelola hubungan masyarakat di Kuttab Al Fatih.

Kategori data yang diungkapkan dalam riset ini merupakan bersifat skematik, ialah berbentuk narasi serta penjelasan juga uraian informasi dari informan baik lisanmaupun informasi dokumen yang tertulis, sikap subjek yang diamati di lapangan juga jadi informasi dalam pengumpulan hasil riset ini. Jenis informasi yang diartikan bisa berbentuk rekaman serta video, catatan lapangan, dokumentasi serta gambar. Sumber data utama ataupun informan kunci dalam riset ini merupakan Kepala Kuttab yang bernama
Dhika Kameswara setelah itu diikuti informan berikutnya secara bergulir bersumber pada yang sudah direkomendasikan informan sebelumnya (snowball process) ialah pengurus Kuttab yang bernama Ahmad serta Divisi Tawaf yang bernama Reza. Sedangkan sumber data tambahan yakni data yang diperoleh dari sumber lain (Creswell, 2014). Data ini diperoleh dari data-data arsip, dokumen formal, buku- buku yang relevan serta informasi pendukung lain yang dijadikan sumber informasi dalam riset kualitatif di Kuttab Al Fatih. Data pendukung bisa berperan sebagai upaya pengecekan terhadap informasi primer yang sudah didapatkan.

Riset ini dilakukan di Kuttab Al Fatih yang beralamatkan di Kp. Dayeuh Pamokolan RT 1/ RW 10 Nomor. 6 Desa Cimenyan Kecamatan Cimenyan Bandung Jawa Barat. Alasan pemilihan sekolah ini merupakan pertama, sistem serta konsep pendidikan yang digunakan di lembaga ini merujuk sistem pembelajaran pada era kejayaan Islam. Kedua, lembaga pendidikan model Kuttab sedikit dikenal oleh orang. Ketiga, lembaga pendidikan ini berstatus nonformal serta mempunyai cabang di 25 kota se-Indonesia, kota Bandung sendiri ialah salah satu cabangnya (Faisal, 2019b). Metode yang dipakai dalam pengumpulan informasi ialah: metode observasi berperanserta (Participant observation), metode wawancara, serta metode dokumentasi (Milles, Matthew B \& Huberman, 1992).

\section{HASIL PENELITIAN DAN PEMBAHASAN}

Berdasarkan temuan peneliti mengenai Sumber Daya Manusia Humas di Kuttab Al Fatih dipegang oleh divisi official Kuttab Al Fatih yang merangkap tugas sebagai divisi Qonuni (kurikulum) dan ditambah oleh divisi Tawaf (Ta'awun dan wakaf) yang artinya saling tolong menolong dan wakaf. Divisi official ini menjadi penghubung antar pengelola Kuttab dan antara pengelola Kuttab dan orang tua sedang divisi tawaf ini menjadi penghubung antara kuttab dan masyarakat sekitar. Divisi Tawaf adalah divisi yang terpisah dari lembaga Kuttab Al Fatih namun masih ada kaitannya dengan Kuttab. Jika Kuttab Al Fatih adalah lembaga yang bergerak dibidang pendidikan maka Tawaf adalah lembaga yang khusus bergerak dibidang sosial dan pendanaan (wakaf). Tawaf juga yang merekrut dan mengurus masyarakat sekitar yang menjadi pegawai kebersihan, pegawai bangunan dan supir jemputan serta menyediakan fasilitas kuttab seperti kursi untuk kebutuhan masyarakat sekitar yang sedang melangsungkan acara walimatul 'urs (tasyakuran menikah) atau tasyakuran khitan (Bidang Kurikulum, 2019; Faisal, 2019a).

Pemisahan ini bertujuan agar lembaga Kuttab Al Fatih hanya fokus pada pendidikan, tidak 
ikut tercampur dengan urusan bisnis atau pendanaan. Divisi Tawaf ini berguna untuk menutupi kekurangan-kekurangan kebutuhan $K u t t a b$, dengan tujuan agar target Kuttab tercapai. Target yang ingin dicapai tersebut adalah menjadikan SPP Kuttab setiap tahun turun bahkan sampai berstatus gratis namun gaji guru selalu naik. Media komunikasi yang digunakan di kuttab $\mathrm{Al}$ Fatih berbeda-beda menyesuaikan dengan sasaran dan tujuannya. Media yang digunakan antara lain mading tiap kelas, surat, telepon, sms. sosial media Instagram dan Facebook, serta aplikasi Whatapps. Jenis komunikasi yang dilakukan juga berbedabeda disesuaikan dengan tujuan dan target sasaran. Ada yang formal ada juga yang informal. Ada yang berbentuk tulisan ada juga yang berbentuk lisan.

Saluran atau media komunikasi yang dipergunakan dalam berkomunikasi dengan publik internal Kuttab yang terdari dari tenaga pendidik dan kependidikan baik itu dari official maupun dari divisi Tawaf adalah saluran komunikasi formal dan informal. Saluran atau media komunikasi formal yang digunakan berbentuk rapat, mading tiap kelas, surat, komunikasi langsung antar sesama pengelola Kuttab baik percakapan lisan maupun percakapan melalui telepon, sms, dan aplikasi whatapps. Sedangkan saluran atau media komunikasi informal yang digunakan berbentuk obrolan di lingkungan Kuttab Al Fatih.

Saluran atau komunikasi yang dipergunakan dalam komunikasi dengan publik eksternal Kuttab yang terdiri dari orang tua, masyarakat sekitar atau lembaga lain adalah saluran komunikasi personal dan massa. Komunikasi personal dilakukan ketika menerima kunjungan tamu baik itu dari orang tua, masyarakat maupun lembaga lain. Dilakukan pula melalui telepon, berkirim sms, chat personal di aplikasi whatapps dan surat. Komunikasi massa dilakukan dengan cara bersilaturahmi. Hal yang dilakukan adalah mengunjungi beberapa rumah terutama tokoh masyarakat yang ada di sekitaran kuttab. Mengajak mereka berbincang-bincang mengenai kehidapan sehari-harinya, kebudayaannya, mata pencahariannya sampai pada pemahaman dan opini mereka tentang pendidikan terutama lembaga pendidikan Kuttab. Cara lain yang digunakan adalah menggunakan fitur grup di aplikasi whatapps. Divisi official dan Tawaf pun bekerja sama dengan divisi media untuk menginformasikan kegiatan Kuttab melalui sosial media Facebook dan Instagram Kuttab Al Fatih Bandung sebagai bentuk komunikasi massa. Penggunaan berbagai jenis saluran atau media komunikasi ini disesuaikan dengan jenis informasi yang ingin disampaikan.

Pemberian informasi yang mengharuskan orang tua datang ke kuttab Al Fatih langsung adalah informasi yang berkaitan dengan pendaftaran santri baru dan informasi yang bersifat pribadi yang bertujuan untuk berkonsultasi.
Pemberian informasi yang menggunakan surat adalah jenis informasi yang bersifat undangan acara resmi seperti acara parade tasmi dan pembagian rapor. Selain dari pada itu semuanya bisa menggunakan media whatapps atau sms.

\section{Perencanaan Hubungan Masyarakat di Kuttab Al Fatih}

Setiap organisasi atau lembaga perlu melakukan perencanaan, termasuk lembaga Kuttab Al Fatih. Perencanaan di Kuttab Al Fatih terbagi menjadi dua yaitu perencanaan anggaran dan perencanaan program. Perencanaan anggaran disusun oleh Kepala kuttab ketika pertengahan semeter dua. Anggaran ini disusun untuk satu tahun kedepan dan hanya diketahui oleh kepala Kuttab, pengelola dan divisi keuangan. Oleh divisi keuangan anggaran disusun kembali untuk per satu bulan kemudian diajukan kepada pengelola. Pengajuan atau penagihan dana untuk kebutuhan satu bulan ini dinamakan Permohonan Uang Muka (PUM) dan diakhir bulan memberikan laporan selama satu bulan tersebut kepada pengelola. Laporan ini dinamakan Pertanggung jawaban Uang Muka (PJUM). Selain itu dari pihak Kuttab pun memberitahu rencana anggaran ini kepada pembina Tawaf. Hal ini sebagai acuan bagi tawaf untuk membantu bila sekiranya Kuttab mengalami kekurangan. Namun pihak Tawaf pun tetap membuat anggarannya sendiri di awal tahun ajaran baru (Thoriqul, 2015).

Perencanaan program dilakukan dalam bentuk rapat mingguan, rapat bulanan, dan rapat kerja (raker). Raker diselenggarakan pada awal tahun ajaran baru yang melibatkan seluruh pengelola Kuttab. Namun sebelum raker diselenggarakan, kepala Kuttab beserta para koordinator divisi termasuk divisi Tawaf mengadakan perkumpulan untuk membicarakan materi yang nanti akan dibahas dalam raker. Materi yang dipersiapkan setidaknya $80 \%$ sudah selesai. Hal ini dilakukan berdasarkan pertimbangan dan prediksi bahwa peserta yang akan hadir dan yang akan menyampaikan opininya cukup banyak sehingga akan memakan waktu yang cukup lama. Dalam raker hal yang dibahas antara lain evaluasi tahun sebelumnya, menganalisis masyarakat dan menyusun program/kegiatan yang akan dilakukan; Evaluasi tahun sebelumnya, Informasi ini didapat dari pemaparan para peserta raker tentang kondisi dilapangan (kondisi Kuttab). Adapun yang dievaluasi adalah jumlah kehadiran dan keikutsertaan guru,orang tua, masyarakat sekitar dalam kegiatan Kuttab, dampak yang dirasakan dari kegiatan-kegiatan Kuttab, per-masalahan dan kendala yang dihadapi (Chotimah, 2013).

$$
\text { Mengenal/menganalisis Masyarakat; }
$$
Menganalisis masyarakat bisa menjadi sarana untuk mengetahui posisi organisasi, dan latar belakang masyarakat. Masyarakat yang dianalisis 
atau yang dikaji adalah guru, orang tua dan masyarakat sekitar/ masyarakat yang bersangkutan dengan Kuttab. Informasi kondisi masyarakat sekitar didapat dari pemaparan kepala Kuttab, official Kuttab dan divisi Tawaf. Pemaparan ini berdasarkan hasil silaturahmi mereka dengan masyarakat. Informasi kondisi guru dan orang tua dilihat dari data hasil rekruitmen guru dan rekruitmen santri.

Adapun yang dijadikan rujukan dalam menyusun program adalah visi misi dan profil Kuttab. Kuttab Al Fatih adalah lembaga nonprofit maka semua kegiatan publikasi bertujuan untuk infomasi bukan promosi walau seperti itu Kuttab tetap harus membangun hubungan yang baik dan melakukan interaksi sosial yang baik. Kuttab telah menentukan program-program, waktu penyelenggaraanya, serta khalayak sasarannya. Program tersebut adalah memfasilitasi masyarakat dalam berkomunikasi dengan kuttab, menyelenggarakan kajian POSKu dan mengadakan program Belajar Bersama Orang tua (BBO). Adapun program yang ditetapkan oleh divisi Tawaf yaitu kegiatan ramadhan, kegiatan Idul Adha, dan program insidentil.

Tabel 1. Program dan Tujuan Kuttab Al Fatih

\begin{tabular}{|c|c|c|c|}
\hline No & Program & Waktu & Khalayak Sasaran \\
\hline 1 & $\begin{array}{l}\text { Memfasilitasi } \\
\text { masyarakat } \\
\text { dalam } \\
\text { berkomunikas } \\
\text { i dengan } \\
\text { kuttab }\end{array}$ & Harian & $\begin{array}{l}\text { Publik internal } \\
\text { dan eksternal } \\
\text { kuttab }\end{array}$ \\
\hline 2 & $\begin{array}{l}\text { Menyelenggar } \\
\text { akan Kajian } \\
\text { POSKu }\end{array}$ & $\begin{array}{l}\text { Satu bulan } \\
\text { sekali }\end{array}$ & $\begin{array}{l}\text { Orang tua santri } \\
\text { yang tergabung } \\
\text { dalam POSKu. } \\
\text { POSKu adalah } \\
\text { singkatan dari } \\
\text { Persatuan Orang } \\
\text { Tua Santri Kuttab, } \\
\text { sebuah wadah } \\
\text { yang berisi } \\
\text { kumpulan orang } \\
\text { tua santri kuttab } \\
\text { Al Fatih. }\end{array}$ \\
\hline 2 & $\begin{array}{l}\text { Mengadakan } \\
\text { kegiatan BBO } \\
\text { (Belajar } \\
\text { Bersama } \\
\text { Orang Tua) }\end{array}$ & $\begin{array}{l}\text { Dua pekan } \\
\text { sekali }\end{array}$ & $\begin{array}{l}\text { Guru dan Orang } \\
\text { tua santri }\end{array}$ \\
\hline 4 & $\begin{array}{l}\text { Mengadakan } \\
\text { kegiatan } \\
\text { ramadhan }\end{array}$ & Ramadan & $\begin{array}{l}\text { Seluruh } \\
\text { stakeholder kuttab } \\
\text { dan orang tua } \\
\text { santri }\end{array}$ \\
\hline 5 & $\begin{array}{l}\text { Mengadakan } \\
\text { kegiatan Idul } \\
\text { Adha }\end{array}$ & $\begin{array}{l}\text { Hari Raya } \\
\text { Idul Adha }\end{array}$ & $\begin{array}{l}\text { Seluruh } \\
\text { stakeholder } \\
\text { kuttab, orang tua } \\
\text { dan masyarakat } \\
\text { sekitar kuttab }\end{array}$ \\
\hline 6 & $\begin{array}{l}\text { Program yang } \\
\text { bersifat } \\
\text { insidentil }\end{array}$ & $\begin{array}{l}\text { Kondision } \\
\text { al }\end{array}$ & $\begin{array}{l}\text { Seluruh } \\
\text { stakeholder } \\
\text { kuttab, orang tua } \\
\text { dan masyarakat } \\
\text { sekitar kuttab }\end{array}$ \\
\hline
\end{tabular}

\section{Implementasi Hubungan Masyarakat Kuttab Al Fatih Bandung: (Bertindak dan Berkomunikasi)}

Implementasi Humas di Kuttab Al Fatih Bandung dilakukan setelah proses perencanaan sudah dilaksanakan dan melibatkan semua pengelola kutab seperti kepala Kuttab, divisi media dan divisi kurikulum. Adapun strategi yang digunakan dalam implementasi humas adalah menjadikan Al-quran, hadits dan sirah nabi sebagai rujukan dalam bertindak dan berkomunikasi. Dengan Membaca kembali sejarah rasul dan para sahabat. Bertindak dan berkomunikasi ini diwujudkan dengan melakukan program-program yang sudah direncanakan yaitu memfasilitasi masyarakat dalam berkomunikasi dengan kuttab, menyelenggarakan kajian POSKu, mengadakan kegiatan Belajar Bersama Orang tua (BBO), menyelenggarakan kegiatan ramadan, kegiatan idul adha, dan program insidentil (Elfridawati Mai Dhuhani, 2016).

Memfasilitasi masyarakat untuk berkomunikasi dengan kuttab; kegiatan ini diantaranya yaitu melayani tamu atau orang tua santri yang datang langsung ke Kuttab Al Fatih ataupun yang menghubungi via sms, telepon atau whatapps, menyebarkan informasi kegiatan Kuttab kepada orang tua santri dan guru, menginformasikan rapat kepada seluruh pengelola Kuttab Al Fatih dan menjadi penghubung antara Kuttab dan masyarakatnya. Pemberian informasi yang mengharuskan orang tua datang ke kuttab Al Fatih langsung adalah informasi yang berkaitan dengan pendaftaran santri baru dan informasi yang bersifat pribadi yang bertujuan untuk berkonsultasi. Pemberian informasi yang menggunakan surat adalah jenis informasi yang bersifat undangan acara resmi seperti acara parade tasmi dan pembagian rapor. Selain dari pada itu semuanya bisa menggunakan media whatapps atau sms (Lailiyah, 2019).

Strategi komunikasi agar memastikan informasi yang disebarkan sampai kepada semua pihak adalah menggunakan media komunikasi handphone berbentuk fitur grup pada aplikasi whatsapp (Satria et al., 2019). Grup ini terdiri dari grup inti, grup koordinator divisi, grup seluruh pengelola Kuttab, grup guru, grup koordinator kelas yang terdari dari orang tua, grup pengurus POSKu dan grup POSKu. Meskipun banyak grup namun hal ini lebih memudahkan pihak official untuk memantau informasi yang sudah sampai dan yang belum sampai dibanding harus menghubungi satu per satu setiap orang. 
Gambar 1. Alur komunikasi pengelola Kuttab Al Fatih

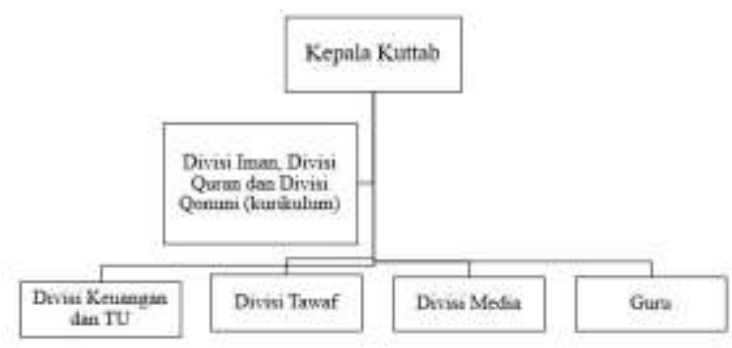

Alur komunikasi menggunakan media whatapps di internal Kuttab dimulai dari kepala Kuttab dan 3 divisi yaitu divisi iman, divisi quran dan divisi qonuni (official Kuttab) dengan membuat grup khusus yang disebut grup inti. Membuat grup inti ini menjadi salah satu strategi agar informasi datang dari satu arah dan menghidari adanya miskomunikasi (Ledingham \& Bruning, 1998; Royal Society for Public Health, 2017). Mereka biasanya mendiskusikan terlebih dahulu konten yang ingin disebarluaskan. Setelah semua selesai didiskusikan, maka disusunlah informasi tersebut oleh official Kuttab, atas persetujuan kepala Kuttab informasi yang sudah disusun pun disebarkan oleh official Kuttab kepada seluruh pengelola Kuttab atau khusus kepada koordinator divisi saja maupun khusus kepada guru saja tergantung jenis pesan yang ingin disampaikan.

Gambar 2. Alur komunikasi untuk orang tua
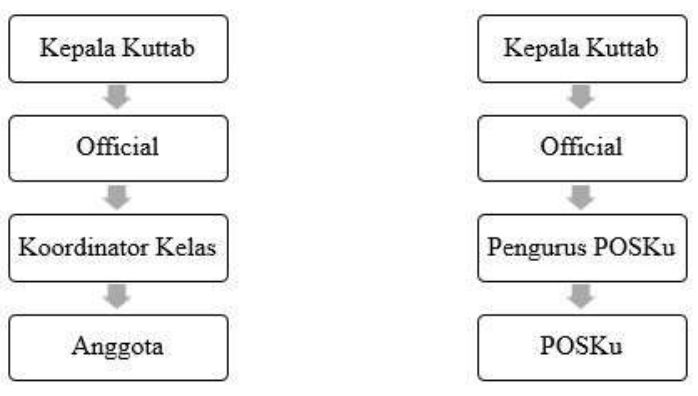

Alur komunikasi menggunakan media whatapps terhadap orang tua terbagi dua yaitu kepada koordinator kelas dan anggotanya serta kepada pengurus POSKu dan anggota POSKu. Informasi dimulai dari Kepala Kuttab, kemudian sampai kepada official Kuttab. Dari official Kuttab pesan diteruskan kepada pengurus POSKu dan koordinator kelas. Pesan yang diteruskan adalah pesan yang sudah disusun oleh official Kuttab atas persetujuan kepala Kuttab. kemudian pesan diteruskan lagi kepada anggota koordinator kelas dan anggota POSKu. Informasi untuk koordinator kelas berkaitan dengan kegiatan pembelajaran santri seperti program BBO. Informasi untuk POSKu berkaitan dengan kajian POSKu dan kegiatan lainnya yang melibatkan orang tua seperti parade tasmi, mabit dan itikaf ketika ramadan (Thoha \& Jannah, 2018).

Menyelenggarakan kajian POSKu; Sejak awal rekruitmen santri, program kajian ini telah dijelaskan kepada orang tua dan telah diadakan perjanjian bahwa orang tua wajib menghadiri kajian tersebut setiap sebulan sekali, apabila dua kali dalam satu semester tidak hadir maka mereka akan dipanggil. Kepala Kuttab pun pada awalnya mengelola langsung kajian POSKu ini karena ketika itu para orang tua belum terlalu aktif mengurus POSKu. Tindakan ini bertujuan untuk mengangkat peran orang tua, namun setelah berjalan beberapa tahun dan setelah peran orang tua sudah mulai terangkat/aktif maka kajian ini di kelola oleh pengurus POSKu (Persatuan Orang tua Santri Kuttab Al Fatih) yang nantinya berkoordinasi dengan pihak Kuttab. materi kajian ini berisi seputar pendidikan. Tempat pelaksanaanya terkadang di luar wilayah kuttab seperti di masjid-masjid maupun gedung serba guna (Dewey, 1904).

Program BBO; Program ini dilakukan dengan memberikan materi oleh guru kepada orang tua yang akan mengajarkan anaknya. Materi tersebut sudah dirangkum dan sudah dibuatkan kisi-kisi beserta tugasnya. Materi ini bebentuk map kemudian map ini diberikan kepada anak, anak kemudian memberikannya kepada orang tua, orang tua lalu membaca, mempelajari dan mengajarkan kembali kepada anaknya dan mengerjakan tugas yang tertera dalam map.

\section{Evaluasi Hubungan Masyarakat Kuttab Al Fatih Bandung}

Salah satu tahap dalam proses tata kelola public relation adalah mengevaluasi program (Hidayat, 2017). Evaluasi dapat dikatakan sebagai usaha atau kegiatan untuk menentukan nilai suatu program atau kegiatan. Evaluasi di Kuttab dilakukan setiap satu minggu sekali, satu bulan sekali dan satu tahun sekali ketika rapat kerja di awal tahun ajaran baru. Untuk divisi tawaf evaluasi dilakukan satu kali per dua pekan. Dalam rapat tersebut semua memaparkan apa saja yang sudah terjadi dilapangan, capaian, kendala dan permasalahan yang dihadapi. Berdiskusi untuk menemukan solusi terbaik atas segala permasalahan yang ada agar tidak terulang lagi di pekan depan ataupun tahun depan (Jahari et al., 2019; Nurdiana \& Prayoga, 2018).

Memfasilitasi komunikasi dan informasi, tujuan program ini adalah agar terjalin komunikasi dan hubungan yang baik antara pihak kuttab, orang tua dan masyarakat. Karena kegiatan ini bersifat harian maka evaluasinya pun dilakukan setiap hari atau ketika sudah selesai menyebarkan informasi (Priandono, 2019). Program ini berjalan dengan lancar hanya saja ada beberapa orang tua yang kurang fokus dan kurang memperhatikan ketika 
menerima informasi sehingga informasi terlambat sampai kepada orang tua. Kajian POSku; Program ini bertujuan untuk memberikan pemahaman terhadap orang tua tentang konsep pendidikan Kuttab. Pemahaman bahwa peran dan tanggung jawab pendidikan anak ada pada orang tua. Pemahaman bahwa Kuttab hadir untuk membantu orang tua dalam pendidikan anak seperti mengenalkan konsep dan cara mendidik anak. Adapun yang dibahas dalam evaluasi adalah mengenai jumlah kehadiran orang tua dan dampak dari adanya program atau perubahan sesudah adanya program. Kehadiran orang tua dalam menghadiri kajian selama satu semester terakhir mencapai 93\%. Dampak bisa dilihat kedekatan orang tua dan pengelola kuttab serta dari sisi perkembangan dan pertumbuhan santri. Jika perkembangan dan pertumbungan santri lambat maka peran orang tua belum berjalan. Program ini sudah berjalan dengan lancar tetapi masih ada beberapa orang tua yang belum memahami sepenuhnya pola pembelajaran di kuttab Al Fatih Bandung .

Kegiatan BBO; tujuan program ini adalah untuk mengembalikan lagi kebiasaan orang tua belajar dengan anak. Karena Kuttab bukanlah lembaga penitipan anak yang ketika orang tua menitipkan anaknya maka orang tua lepas tangan. Sesungguhnya tanggung jawab terbesar terletak pada orang tua sedangkan pihak Kuttab hanya membantu. Jika anak berhasil pun Kuttab tidak akan mengklaim bahwa itu adalah keberhasilan dari didikan Kuttab. Itu adalah hasil peran orang tua, bukan hanya ibunya tetapi juga ayahnya. Adapaun yang menjadi bahan evaluasi ada dilihat dari sisi perkembangan santri dalam belajar dan mampu menyelesaikan tugas yang sudah diberikan. Program ini berjalan dengan lancar.

\section{KESIMPULAN}

Berdasarkan hasil penelitian yang dilakukan pada proses pengolahan data, dapat diambil kesimpulan bahwa; Pertama, perencanaan hubungan masyarakat telah dilakukan sesuai dengan langkah-langkah perencanaan mulai dari perencanaan anggaran, perencanaan program, mengkaji lingkungan internal dan eksternal, menetapkan khalayak, dan memilih media. Perencanaan ini dilakukan satu tahun sekali. Perencanaan ini mengacu pada visi misi dan profil Kuttab yang merujuk kepada Al-quran, hadits dan sirah nabi. Materi perencanaan sebagian telah didiskusikan terlebih dahulu oleh Kepala Kuttab dan koordinator divisi. Barulah untuk materi perencanaan keseluruhan dibahas pada rapat kerja yang melibatkan seluruh pengelola Kuttab. Dari perencanaan melahirkan program-program yang mendukung terhadap hubungan masyarakat di Kuttab Al Fatih Bandung; kedua, implementasi hubungan masyarakat mengacu pada perencanaan yang sudah dibuat. Implementasi hubungan masyarakat Kuttab Al Fatih berbentuk program yang terbagi kedalam tiga jenis hubungan kerjasama masyarakat dengan kuttab yaitu hubungan educational berupa program kajian POSKu dan progam BBO, hubungan kultural berupa kegiatan Idul Adha, kajian ramadan, dan bakti sosial dan hubungan institusional berupa kerjasama antara kuttab dan aparat setempat; Ketiga, evaluasi hubungan masyarakat di Kuttab Al Fatih dilakukan satu tahun sekali, satu semester sekali, satu bulan dan satu minggu sekali. Hal yang dievaluasi berasal dari fakta dilapangan terkait capaian, kendala dan permasalahan yang dihadapi. Dari semua program yang direncanakan seluruhnya berjalan dengan baik hanya ada beberapa kendala diantaranya yaitu kurangnya respon orang tua terhadap informasi yang disebarkan dan ada beberapa orang tua maupun masyarakat sekitar yang masih beradaptasi dengan pola pembelajaran di kuttab Al Fatih.

\section{DAFTAR PUSTAKA}

Bidang Kurikulum. (2019). Visi misi Kuttab AlFatih Bandung. Official Website Al-Fatih. http://kuttabalfatih.com/web/profil/visi=misi/

Chotimah, C. (2013). Manejemen Publik Relation Integratif. STAIN Tulung agung Press.

Creswell, J. W. (2014). Research design: qualitative, quantitative, and mixed methods approaches (IV). SAGE Publications, Inc.

Dewey, J. (1904). The relation of theory to practice in education. The Relation of Theory to Practice in the Education of Teachers (Third Yearbook of the National Society for the Scientific Study of Education, Part I).

Elfridawati Mai Dhuhani. (2016). Manajemen Humas dalam Meningkatkan Mutu Madrasah Studi Kasus di Madrasah Terpadu (MIT) AsSalam Ambon. Jurnal Altizam.

Faisal, P. (2019a, April). Latar Alamiah Lembaga Pendidikan Kuttab Al-Fatih Bandung. https://www.kuttabalfatih.com/?fwportfolio=madrasah-alfatih

Faisal, P. (2019b, December). Profil Lembaga Pendidikan Kuttab Al-Fatih Bandung. Official Website Al-Fatih. https://www.kuttabalfatih.com/project/bandu ng

Hidayat, D. (2017). Manajemen Humas Dalam Meningkatkan Hubungan Kerjasama Sekolah Dengan Masyarakat di Smp Nahdatul Ulama Medan. Benchmarking - Jurnal Manajemen Pendidikan Islam, I(1). http://jurnal.uinsu.ac.id/index.php/benchmark ing/article/view/1115

Jahari, J., Prayoga, A., \& Paramudita, A. (2019). Tata Kelola Kearsipan Di Kantor Pendidikan Madrasah Kementerian Agama Kabupaten Sumedang. In Kariman (Vol. 7, Issue 2). 
https://inspektorat.sumbarprov.go

.id/details/news/9153

Jahari, J., \& Sarbini, A. (2013). Manajemen Madrasah: Teori, Strategi, dan Implementasi (1st ed.). CV. Alfabeta.

Lailiyah, N. (2019). Analisis Kegiatan Public Relation Untuk Membangun Brand Awerness di PT Victory International Futures. Jurnal Studi Manajemen Dan Bisnis. https://doi. org/10.21107/jsmb.v6i2.6685

Ledingham, J. A., \& Bruning, S. D. (1998). Relationship management in public relations: Dimensions of an organization-public relationship. Public Relations Review. https://doi. org/10.1016/S03638111(98)80020-9

Milles, Matthew B \& Huberman, M. A. (1992). Analisis Data Kualitatif. Universitas Indonesia (UI-Press).

Moleong, L. J. (2017). Metodologi Penelitian Kualitatif (Edisi Revisi). In PT. Remaja Rosda Karya.

Nurdiana, M., \& Prayoga, A. (2018). FungsiFungsi Manajemen dalam Kegiatan Ekstrakurikuler Pramuka di Madrasah. Madrasa: Journal of Islamic Educational Management, $\quad$ 1(0), 9-15. http://madrasa.id/index. $\mathrm{php} / \mathrm{madrasa} /$ article/view/2/2

Priandono, F. (2019). Manajemen Humas Pendidikan Dalam Upaya Pencitraan Sekolah di Sekolah Menengah Kejuruan. At-Ta'lim : Media Informasi Pendidikan Islam, 18(2), 391-410. https://doi.org/10.29300/atta lim.v18i2.1740

Royal Society for Public Health. (2017). Social media and young people' s mental health and wellbeing. Royal Society for Public Health,.

Satria, R., Supriyanto, A., Timan, A., \& Adha, M. A. (2019). Peningkatan Mutu Sekolah melalui Manajemen Hubungan Masyarakat. Jurnal Akuntabilitas Manajemen Pendidikan, 7(2), 199-207. https://doi.org/10.21 831/amp.v7i2.26018

Sugiyono. (2016). Metode Penelitian kuantitatif, kualitatif dan $R \& D$ (24th ed.). Alfabeta.

Thoha, M., \& Jannah, I. N. (2018). Public Relation dan Pembangunan Citra Agamis. Research Journal of Islamic Education Management.

Thoriqul, C. M. (2015). Kuttab; Lembaga Pendidikan Islam Klasik. Al-Murabbi, 01(02). 